\title{
Exploring Student Experiences on the Use of Blackboard in a Blended Learning class: A Case Study at a South African University
}

\author{
Ms. Siyanda Ntlabathi \\ University of Fort Hare \\ E-mail: sntlabathi@ufh.ac.za
}

\section{Doi:10.5901/mjss.2014.v5n11p89}

\begin{abstract}
A Learning Management System (LMS) called Blackboard was used in a first year course as a support tool for a Blended Learning class in a Higher Education environment. The aim behind the use of the tool was to allow student easy, flexibly access to class materials and to improve the students' learning experience. Therefore this paper reports on the findings concerning student experiences in the implementation of Blackboard in a Blended Learning classroom environment. The study adopted a quantitative approach using a survey as the research design. A questionnaire was administered to hundred and sixty four students in a first year class. The data collected was analysed using the Lickert scale. Illustrations were done through tables and charts to showcase the results. The results of the study demonstrated increasing positive use, with more efficiency and satisfaction amongst students. The study concludes that the LMS allowed for more efficiency in administration and accessing of class materials, improved communication with the Lecturer and discussions amongst students. The recommendations of the study are that students should be trained well in the use of the LMS and sufficient computer resources should be made available.
\end{abstract}

Keywords: Blended Learning, Learning Management Systems, Blackboard, Higher Education, Flexibility, Accessibility

\section{Introduction}

Blended Learning is described similarly by most writers who conduct studies in this area. The two most prominent definitions that are in par with the researcher's understanding of Blended Learning are by, Laurillard, (2002) defines Blended Learning as an approach to education that combines face-to-face interaction with use of technologies; Rooney, (2003); Ward \& LaBranche, (2003) define Blended Learning "as a combination of online and face-to-face instruction." These definitions conquer with my understanding of the idea of Blended Learning. Blended Learning uses a combination of different media to support and enhance face to face interaction, which is why in some text it is referred to as a mix or hybrid mode of learning (Garrison and Kanuka, 2004).

For the purposes of this study a technology in the form of software called Blackboard was used. Blackboard is categorised as a Learning Management System which can be used in combination with face to face interaction. Blackboard provides an online space where there are a variety of tools which can be used to enhance ones teaching and learning experience. A Learning Management System (LMS's) on the other hand is described as a collection of eLearning tools available through a common interface. It can be thought of as a platform in which online courses are developed and accessed (Nichols, 2003). LMSs are an integral tool for facilitating exciting, meaningful, and active learning experiences. According to Connolly \& Stansfield (2006), Blended Learning has "overwhelmingly changed many aspects of society and inevitably, it is having a significant impact on Higher Education, where it has now advanced from a marginal form of education to a commonly accepted alternative to traditional face-to-face education". Since technologies are promoting access and flexibility (Bonk \& Graham, 2005) by enabling educators worldwide to engage with learners anywhere and at any time using technology enhanced approaches (Fallows \& Bhanot, 2002), Higher Education institutions have come to be characterised by the use of many technological tools to enhance teaching and learning.

The use of these technologies in the Higher Education landscape as outlined above has important implications for curriculum design and the use of technology in teaching and learning. While these technologies are in most cases initiated in response to both global and local imperatives, the technologies themselves require new practices and requirements for curriculum and learner support in the $21^{\text {st }}$ century (Pearlman, 2010). This century is categorised by a rise in a very diverse range of technological advancements, of which most notably in the context of Higher Education is the emergence of smart phones which encompass mobile technologies like androids and iPods. Surrounded by technology in every sphere of their lives our students are characterised as $21^{\text {st }}$ century learners. Due to the advancement 
of information and communication technologies (ICTs) and the concept of a $21^{\text {st }}$ century learner, it has become impossible to ignore the implications of these technologies for teaching and learning. Technologies such as Learning Management Systems (LMSs) are designed to enhance teaching and learning and others such as blogs and wikis which are appropriated for educational purposes have much potential to transform lecturers' practices with regard to teaching. In order to realise the potential of these digital technologies, it is appropriate that we study the impact they have on our student in the teaching and learning environment.

The recent introduction of technologies like Blackboard at the institution understudy is believed to be one of the responses to the imperatives of dealing with skills shortages and facilitating the needs of the $21^{\text {st }}$ century learner in this particular context. Since ICTs are affecting the 21st century student in every aspect of their lives inside and outside the university, it is important to engage students with ICTs within the university and to explore their experiences of how these technologies impact their learning environment. Due to the residential nature of the University, a Blended Learning approach through the integration of the Blackboard technology into teaching and learning was felt to be appropriate by the researcher concerned.

In contrast to much of the developed world, the lack of basic technological infrastructure is a big challenge in Africa (Department of Education, 2004). This is widening the gap between Africa and the developed world. To address this issue, Africa adopted a renewal framework called the New Partnership for Africa's Development (NEPAD) which identifies ICTs as an integral part of teaching and learning in higher education (ibid.).

According to the White Paper on e-Education (Department of Education, 2001), the overture of ICTs in education signify a key area of Government's strategy to improve the quality of teaching and learning across the education and training spectrum. The intention of the e-Education policy is to focus on teaching and learning for a new generation of young people who are growing up in a digital world and are comfortable with using technology (Department of Education, 2004). The e-Education policy intention is not just to build technical skills, but also to extend and enrich educational experiences across the curriculum (ibid.).

Implementation of e-Learning or online environments in South African higher education institutions is different from institution to institution (Czerniewicz, 2007). This reflects the variety in organisational cultures and approaches as well as varied learner communities served by different institutions.

The term e-Learning covers different delivery modes ranging from courses that are delivered through distance education online (with no face-to-face meetings) to courses that provide some face-to-face interaction and some online provision (referred to as "blended learning"). The Sloan Consortium, (2005) identifies three formats based on delivery modes and proportion of content delivered online: completely online courses, blended courses, and web-facilitated courses. In all these formats, LMSs are an integral tool for facilitating exciting, meaningful, and active learning experiences.

There is a lot of research on emerging technologies used for Blended Learning, but research specific to the Blackboard LMS in Blended Learning environments is limited, yet the research available expresses their adaptability. According to Beldarrain, (2007) Wikis are supple enough to be used for a range of purposes and be adapted in different courses, such as those teaching writing or even biology. This paper aims to report on the experiences of students who are introduced to a LMS called Blackboard in a Blended Learning environment in their first year class. As much as the context is that of a Blended Learning environment, the study looks at their experiences with the use of Blackboard where they were using the tool to communicate with the lecturer, access course materials and participate in online discussion forums.

\section{Aim of the Study}

This paper aims to explore student experiences on the use of Blackboard in a Blended Learning class. The aim will be realised through the following Research Questions;

1. What are the challenges faced by students with the use of Blackboard in a Blended Learning environment.

2. What are the benefits envisaged by students in using Blackboard for blended learning environments.

3. What support do students need in a blended learning environment?

\section{Methodology}

\subsection{Research Design}

The research design employs a case study approach within a quantitative research methodology using a small scale 
survey to source data.

\subsection{Population and Sampling}

The data collected is comprised of a sample size of 215 students that were purposively selected in a first year class where only 154 students responded to the questionnaire. The questionnaire was specifically administered to be analysed using the Lickert scale method. A cover page was attached to the questionnaire that informed the students of the aims of the study, the time envisaged to respond to the questionnaire and their right to participant or withdraw. Confidentiality was also addressed.

\subsection{Data Analysis}

A survey was conducted through a questionnaire to source students experiences about Blackboard. Students were asked to indicate their experiences using a Likert scale. They had to check "1" if they strongly agree, "2" if they agree, "3" if they strongly disagree, and "4" if they disagree. The questionnaire entailed questions that were concerned with benefits, challenges and support issues that would affect the student.

\section{Survey Results and Discussion}

The survey results and responses are presented in the format of tables and charts with a narration describing and discussing the findings. The results are categorised according to the challenges, the benefits and the support needs of students in the use of blackboard in a blended learning environment.

\subsection{Challenges faced by students:}

The first results that are presented below show the challenges faced by students when using Blackboard as a Blended Learning tool. Under challenges experienced there are two areas of contestation, lack of computers skills and unavailability of computers.

\subsubsection{Computer skills}

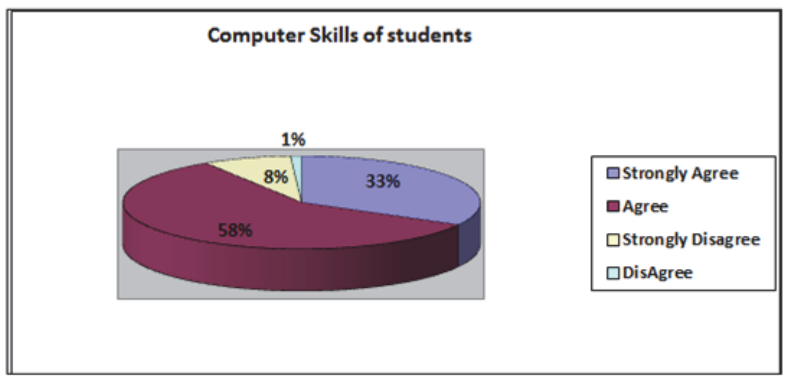

Figure 1: A representation of the Computer Skills of students

The findings as represented in Figure 1, above indicate that 33\% strongly agree and $58 \%$ agree that they had sufficient computer skills and $8 \%$ strongly disagree and $1 \%$ disagree that they lacked computer skills. This indicates that using a computer was not the main challenge for the majority of students. This means that the student's competence in using a computer was not a major challenge for $88 \%$ of the students but the $9 \%$ that are still struggling will need to be supported It is to be acknowledged that lack of computer skills can be a hindrance and frustrating factor in a learning environment especially that the students had to access their materials through Blackboard. The issue of computer skills can lead to students being shy to acknowledge to their peers that they do not know how to use a computer, and this may hinder their progress. According to (King, 2002; Welker and Berardino; Mc Veigh, 2009) this prohibits the students' abilities to engage in on-line activities, suggesting that more support needs to be provided to students who are involved in Blended Learning 
environments. Smyth, Houghton, Cooney and Casey, (2011) suggest that offering support may take the shape of additional basic computer skills as well as training in the use of the online tool.

\subsubsection{Adequate availability of Computers}

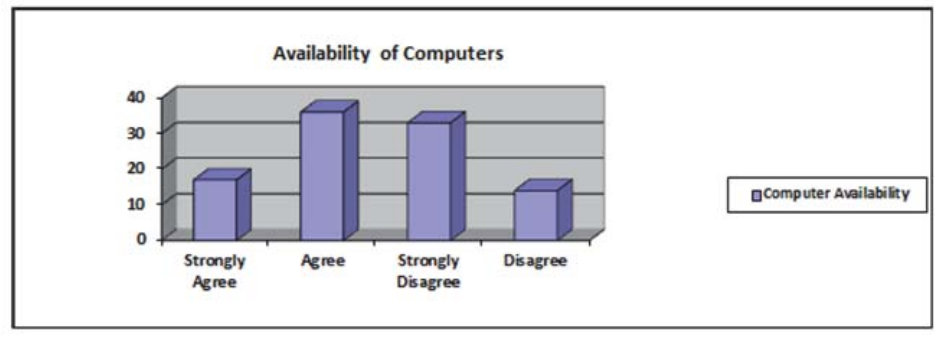

Figure 2: Adequate availability of Computers

With the adequate availability of computers almost $50 \%$ of the students see this as a challenge and $50 \%$ agree that computers are always available. It is well and good that $50 \%$ of the students believe that computers are adequately available, but there is another $50 \%$ that feels they are not adequately available. Many factors can be attributed to this, for example, this involves the time when the student is free to go to the lab. It can also be an issue of when the student is available, maybe when they are free to access computers also other students are free to access the computer lab. This then becomes a challenge as open access computer laboratory's can only accommodate a certain no of students. If students need access to the computer laboratory at the same time, then the laboratory's will always be full. Booking of computer laboratory's time might solve the problem, but because this has not been tried out yet, there is no guarantee that bookings will work. Garrison and Kanuka, (2004) argue that "the need to carefully assess the resources required to implement and sustain effective blended learning environments cannot be overemphasized". They suggest that reliable and transparent technical resources are required to ensure that the technology can enhance the learning process-rather than obstruct it (Garrison and Kanuka, 2004).

\subsection{Benefits from use of Blackboard}

The benefits of using Blackboard for Blended Learning environments in this context are evident in the tables 3 and 4 below as students express their experiences. Benefits were highlighted in two areas 1 ) in availability of course materials and 2) weather Blackboard motivates students to learn.

\subsubsection{Availability of Course Materials}

\begin{tabular}{|c|c|c|}
\hline & Frequency & Percentage \\
\hline Strongly Agree & 65 & $42 \%$ \\
\hline Agree & 77 & $50 \%$ \\
\hline Strongly Disagree & 9 & $6 \%$ \\
\hline Disagree & 3 & $2 \%$ \\
\hline
\end{tabular}

Figure 3: A tabular representation on availability of course materials

When one combined the total number of students who have strongly agreed and those who agreed, the total was $92 \%$ as opposed to those who strongly disagree and disagree which totaled to $8 \%$. This means that student were very pleased with the availability of materials online through Blackboard. This suggests that materials became easily accessible to students as they did not need to go to the lecturers office or to their peers to get course materials, they could easily download the course materials through Blackboard. This also suggests flexibility in terms of access from anywhere and anytime, for those students with 24 hour access to the internet, which allows for interaction and engagement at anytime from anywhere. Beldarrain, (2007) argues that technology may enhance collaboration and interaction. Whilst Kearsley \& Shneiderman, (1999) suggest that engagement theories ascertain that technology can achieve positive variety of 
engagements and interactions that would otherwise not be achievable with the traditional methods.

\subsubsection{Blackboard is motivating towards my learning.}

\begin{tabular}{|c|c|c|}
\hline & Frequency & Percentage \\
\hline Strongly Agree & 54 & $35 \%$ \\
\hline Agree & 51 & $33 \%$ \\
\hline Strongly Disagree & 14 & $9 \%$ \\
\hline Disagree & 35 & $23 \%$ \\
\hline
\end{tabular}

Figure 4: A tabular representation on whether Blackboard was a motivating factor in student learning.

As to whether the use of blackboard motivates students, the results indicate a total of $68 \%$ combining those who strongly agreed and those who agreed. The ones who strongly disagree and those who disagreed totaled to $32 \%$. This indicates that the student motivation level of $68 \%$ was very good and their learning process improved. This might imply that the use of Blackboard cannot be the only motivating factor for a student to learn as there is only $68 \%$. Whilst $32 \%$ disagreed, it is again evident that if such a large number (32\%) can disagree, then Blackboard use was surely not a major motivating factor for the students learning experience. Bandura's (1977) as cited by Beldarrain, (2007) suggests that social learning theory places a high value on observation and modelling behaviours. It deduces human behaviour as the product of a person's interaction with the cognitive, behavioural, and environmental pressures that encircle him. He believes that the current technological tools have very little or no modelling strategies at all that would have assisted in the learning process.

\subsection{Support in use of Blackboard}

Support is another area of importance when implementing a new technology for both students.

\subsubsection{Sufficient support in the use of Blackboard;}

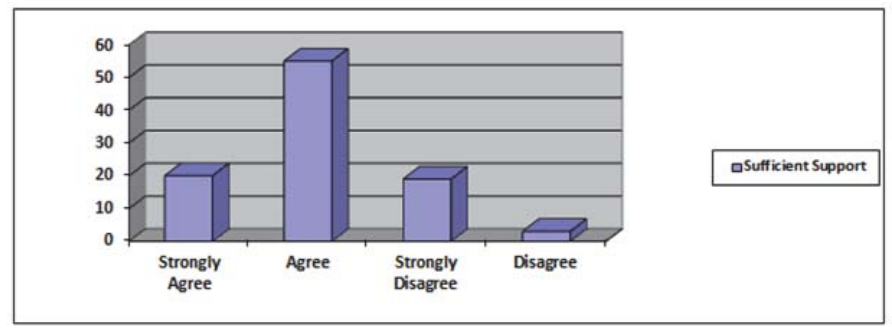

Figure 5: A graphical representation on sufficient support in the use of Blackboard

The chart indicates an overwhelming $75 \%$ of student's response in that sufficient support was provided, with the rest of the $25 \%$ feeling that there was no adequate support provided. Support for students is a very important component of blended learning as it can hinder student progress. Garrison and Kanuka, (2004) suggest that at a minimum, providing effective support for blended learning requires an understanding of the course management environment that students will be using, in addition to situational, dispositional, informational, and institutional barriers. McVeigh, (2009) also argues that more support and resources need to be provided for students beginning a blended learning programme. Garrison and Kanuka, (2004) further argue that dedicated student service support centre need to be provided to help students with technology access, which includes not only access to a computers with the necessary software and Internet connections, but also support with the skills necessary to succeed in a blended learning environment.

\section{Conclusion}

The findings suggest that students experienced a positive use and satisfaction with this approach to learning because 
most of them were motivated. That the use of Blackboard allowed for more flexibility in accessing class materials, improved access to the lecturer through interaction in discussions amongst students. The positive experiences on the use of blackboard as a tool in a blended learning environment suggest that the tool can be used to enhance the classroom environment. The findings do suggest a lot of support being needed in the area of computer skills and computer resources. Kearsley and Shneiderman (1999), suggest that as emerging technologies are implemented to support interaction, the lecturer's role will include not just monitoring and facilitating the interactions, but also actively participating in the exchange of knowledge and reflection. Both students and lecturers will benefit from the mutual learning process if they are partners in learning.

\section{Recommendations}

There are two main recommendations from this study that can assist to improve the use of Blackboard in the Blended Learning environment. One entails that more vigorous training should be done on the use of the Blackboard LMS and 2) suggests that sufficient computer resources should be provided for students to access. Another consideration for further research would be to look at how the Lecturers in these Blended Learning environments embed pedagogies plus content and technologies.

\section{References}

Bandura, A. (1977). Social learning theory. New York: General Learning Press.Bonk, C. J., \& Graham, C. R. (2005). The Handbook of Blended Learning: Global Perspectives, Local Designs.

Beldarrain, Yoany. (2006). Distance Education Trends: Integrating new technologies to foster Student interaction and collaboration. Distance Education, 27(2), p139-153.

Connolly, T., \& Stansfield, M. (2006). Using Games-Based eLearning Technologies in Overcoming Difficulties in Teaching Information Systems. Journal of Information Technology Education, 5, 459-476.

Czerniewicz, L. (2007). South Africa. In L. Czerniewicz \& C. Ngugi (Eds.), ICTs and Higher Education in Africa (pp. 89-116). Cape Town, South Africa: Centre of Educational Technology, University of Cape Town.

Department of Education. (2001). National Plan for Higher Education. Pretoria: Department of Education.

Department of Education. (2004). White Paper on e-Education: Transforming Learning and Teaching through Information and Communication Technologies (ICTs). Pretoria: Department of Education.

Fallows, S. J., \& Bhanot, R. (2002). Educational Development through Information and Communications Technology. Staff and educational development series. London: Kogan Page.

Garrison, D. R., \& Kanuka, H. (2004). Blended learning: Uncovering its transformative potential in higher education. Internet and Higher Education, 7, 95-105.

King, K.P., 2002. Identifying success in online teacher education and professional development. The Internet and Higher Education 5 (3), 231-246.

Kearsley, G., \& Shneiderman, B. (1999). Engagement theory: A framework for technology-based teaching and learning. Retrieved January 23,2006 , from http://home.sprynet.com/gkearsley/engage.htm

Laurillard, D. (2002). Rethinking university teaching: A framework for the effective use of educational technology, (2nd ed.). London: Routledge

Nichols, M. (2003). A theory for eLearning. Educational Technology \& Society, 6(2), 1-10.

McVeigh, H., 2009. Factors influencing the utilisation of e-learning in post-registration nursing students. Nurse Education Today 29 (1), 91-99.

Pearlman, B. (2010). Designing New Learning Environments to Support 21st Century Skills. Retrieved from http://www.ieasa.studysa.org/resources/Study_SA/Facts_Figures_section.pdf

Reay, J. (2001). Blended learning - a fusion for the future. Knowledge Management Review, 4(3), 6.

Rooney, J. E. (2003). Blending learning opportunities to enhance educational programming and meetings. Association Management, $55(5), 26-32$

Sands, P. (2002). Inside outside, upside downside: Strategies for connecting online and face-to-face instruction in hybrid courses. Teaching with Technology Today, 8(6).

S. Smyth, S., Houghton, C., Cooney, A., Casey, D., 2011. Students' experiences of blended learning across a range of postgraduate programmes. Nurse Education Today, 32 (2012), pp. 464-468

The Sloan Consortium Growing by Degrees: Online Education in the United States, 2005 - Southern Edition | (2005). Retrieved from http://www.sloan-c.org/publications/survey/growing_by_degrees_2005_southern

Ward, J., \& LaBranche, G. A. (2003). Blended learning: The convergence of e-learning and meetings. Franchising World, 35(4), 22-23.

Welker, J., Berardino, L., 2005. Blended learning: understanding the middle ground between traditional classroom and fully online instruction. Journal of Educational Technology Systems 34 (1), 33-55.

Young, J. R. (2002, March 22). 'Hybrid' teaching seeks to end the divide between traditional and online instruction. Chronicle of Higher Education, pp. A33. 